\title{
Creep of High-Purity Aluminum
}

\author{
William D. Jenkins
}

\begin{abstract}
A study was made of cold-drawn aluminum at $105^{\circ} \mathrm{F}$, to determine the effects of variations of creep rate on the mechanism of deformation. Strain-hardening was found to decrease monotonically with increase in strain during first stage of creep. The extension on loading and the extension at the beginning of the third stage both increased with increase in stress. Cyclic temperature changes appeared to increase the ductility. Discontinuous flow was evidenced in constant-load creep tests at $105^{\circ} \mathrm{F}$ and in tensile tests conducted at $80^{\circ} \mathrm{F}$. Conformance to Andrade's law of transient flow was found within a limited range of strain rates. Sigmoidal curves were produced that depicted the relationship between stress and creep rate. A mechanism of flow based on observed structural changes is proposed.
\end{abstract}

\section{Introduction}

Many empirical formulas have been developed and used with rather limited success to evaluate the relationships between temperature, stress, and creep rate of metals and alloys. Interpretations of these relations are complicated by the various types of flow occurring during the first, second, and third stages of creep. Some investigators, however, agree that movement can occur both at the grain boundaries and within the grains in creep, and that the parent grains break up into crystallites whose dimensions are dependent on such factors as chemical composition, temperature, strain rate, and the stage of the creep test $[1,2] .{ }^{1}$

Discontinuous flow has been observed in creep tests made at this Bureau on annealed high-purity copper [3] and on cold-drawn ingot iron [4]. Further evidence of this phenomenon, observed in the tests with high-purity aluminum, will be discussed in this paper.

\section{Material and Testing Procedure}

All specimens were cut from a $7 / 8$-in. round bar of high-purity aluminum that had been cold drawn to 40 -percent reduction of area. This aluminum contained the following percentages of other elements as determined spectrochemically.

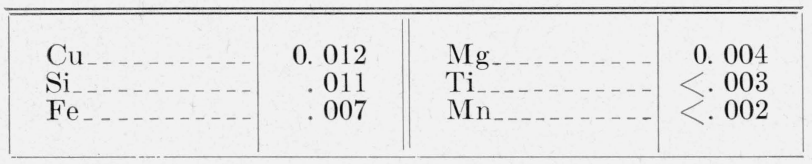

Some properties, at room temperature $\left(80^{\circ} \mathrm{F}\right)$, of the cold-drawn aluminum are as follows:
Yield strength, 0.2-percent offset, psi

Tensile strength, psi

Elongation in 2 in., percent at maximum load

Elongation in 2 in., percent at fracture.

Reduction of area, percent at maximum load

Brinell number, 500-kg load; 10-mm-diameter ball
14,000

17,500

1. 4

20

1. 3

34
${ }_{1}$ Figures in brackets indicate the literature references at the end of this paper
The creep tests were made on round specimens having a gage length of $4 \mathrm{in}$. and a gage diameter of 0.505 in. These tests were carried out in air at a temperature of $105^{\circ} \mathrm{F}$, with the exception of one test for which the temperature was changed from $105^{\circ}$ to $95^{\circ} \mathrm{F}$ and back to $105^{\circ} \mathrm{F}$. The specimens were held at the test temperature for $48 \mathrm{hr}$ before loading, and the rate of loading was controlled so that an average rate of extension of 30 to 50 percent per $1,000 \mathrm{hr}$ was maintained until the desired creep load was obtained. Thereafter the load was not changed until the test was discontinued. The creep-testing equipment has been described in a previous paper [5].

Tension tests also were made at room temperature on specimens similar to those used for the creep tests, and true stress-strain values were determined from simultaneous load and diameter measurements made during these tests. Usual procedures were used in preparing the specimens and in carrying out the metallographic examinations.

\section{Results and Discussion}

\section{Influence of Stress on Plastic Extension During Loading}

A composite stress-extension curve for different specimens loaded at rates of extension of 30 to 50 percent per $1,000 \mathrm{hr}$ is shown in figure 1 . The homogeneity of the material is indicated by the lack of appreciable scatter of the observed values. With this rate of loading the change of strain hardening with strain decreases continuously with increase in stress. These conditions are evidence of the fact that the course of the reaction to a more stable state is speeded as the stress is increased. Similarity to chemical-rate reactions should be noted as the ability of metals to flow is increased by increase in strainenergy. The subsequent work-hardening characteristics are described in succeeding sections.

\section{Extension-Time Characteristics as Influenced by Stress}

The general relation between extension and time during creep of metals and alloys tested in tension at a constant load and a constant temperature can be simply represented by an extension-time curve. For 


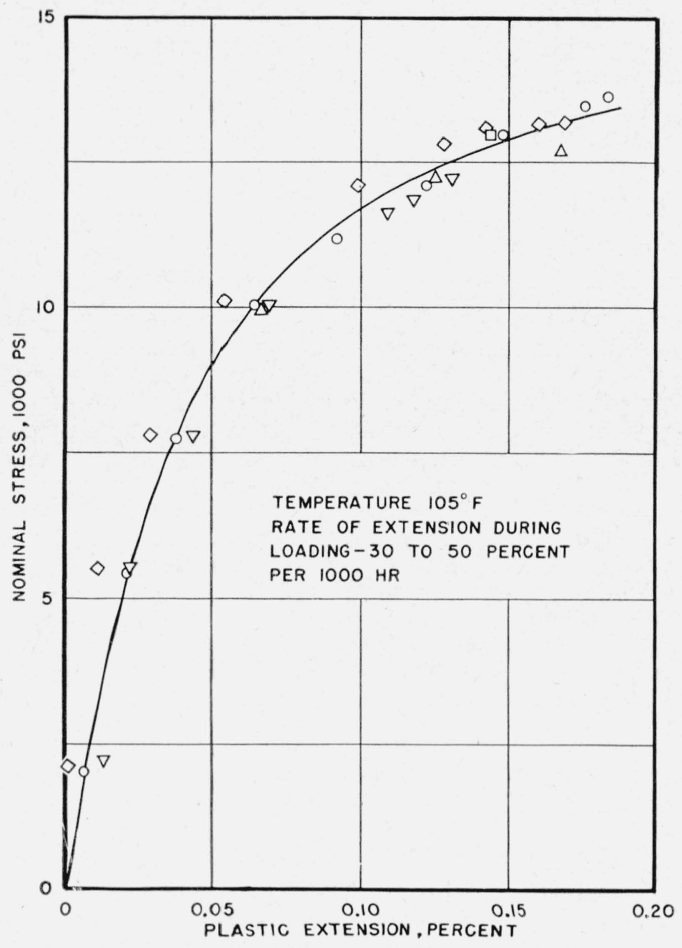

Figure 1. Effect of nominal stress on plastic extension during loading.

Each symbol represents values obtained in individual tests.

ideal conditions, the course of such a curve is divided into parts as follows: (1) An initial extension (elastic and plastic), which occurs on the application of load, (2) a stage of decreasing rate of extension (designated as primary or first stage of creep), (3) a stage of nearly constant rate that attains a minimum (designated as secondary, minimum rate, or second stage of creep), and (4) a stage of increasing rate eventually leading to complete fracture (designated as tertiary or third stage of creep).

The family of extension-time curves for various applied stresses are shown in figure 2. A general examination of these curves shows that, as the applied stress is increased, the time for initiation of each of the stages is decreased, and the initial extension on loading and the extension at the beginning of the third stage are increased. The variation of stress with time to attain some equal value of strain apparently conform to a power relationship; however, no simple qualitative relationship could be established between stress and extension at the beginning of the second stage nor the intercept extension produced by extrapolating the second stage extension-time curve to zero time due to the existing work-hardening and recovery characteristics of the material at various stress levels.

A suggested partial explanation for these phenomena is that the deformation occurs in part by the breaking up of some of the parent crystals into smaller units designated as subcrystals [3], which for a fixed temperature are smaller, the greater the initially applied stress. The factors that produce the smaller units, tend to cause greater hardness and thus increase the rate of strain-hardening; however, due to the randomness of the adjacent subcrystals (figs., 10, $\mathrm{A}$ and $\mathrm{B}$ ) the tendency to recover is more apparent than in larger crystals, and thus greater ductility at the beginning of the third stage is obtained. At this point the atoms are in a more stable position than at any previous strain state, and the increase in free energy of the system with time is at a minimum. The shape of the extension-time curves is further influenced by local imperfections due to plastic deformation in addition to the inherent structural stability of the material and the distribution of the parent grains that did not fragment during deformation. These factors account in part for the transient effects observed when some of the test conditions were altered and then returned to their original state.

\section{Effect of Cyclic Temperature Changes on Creep Characteristics}

The extension-time and creep-rate time diagrams for a specimen tested in creep with a stress of 13,200 psi (consecutively at temperatures of $105^{\circ}, 95^{\circ}$ and $105^{\circ} \mathrm{F}$ ) are shown in figure 3 . The average creep rate before lowering the temperature was 0.37 percent per $1,000 \mathrm{hr}$. The change to the lower temperature did not cause an immediate steady-state rate condition, but rather a gradual reduction in the slope of the extension-time curve. This indicates the presence of a first stage under these conditions. After the attainment of approximately constant rate at $95^{\circ} \mathrm{F}$, the subsequent creep rate on raising the temperature to $105^{\circ} \mathrm{F}$ appeared to be unaffected by previous test temperature. These findings confirm the results presented in a previous investigation with copper [3], which showed that other disturbances could produce entirely different results. The conclusion in such cases was that the subsequent creep rate after temperature change depends essentially on the prior history of the material, despite the fact that changes in test conditions may be expected to alter the flow mechanism. As would be predicted, the creep ratetime cycles, illustrated in the upper portion of figure

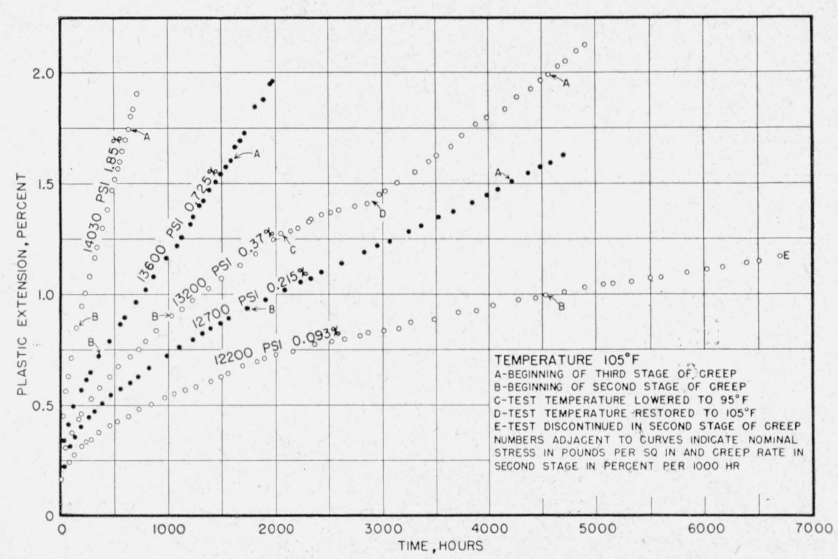

FIGURE 2. Extension-time curves for specimens tested in creep with different initially applied loads. 
3 , are more prominent in the range of lower temperature. The deformation at lower temperature and the thermal gradients set up as a result of the temperature change altered not only the deformation process as reflected in the strain rate-time diagram, but also caused an increase in extension at the beginning of the third stage as was shown in figure 2 . Thus the range at which the free energy of the process is at a minimum is shifted to a higher extension value. Concepts of this type must be accounted for in physical interpretations of the deformation process, as it has been shown previously $[3,4]$ that neither recrystallization on a macro scale nor increase in average true stress is necessarily a prerequisite for initiation of the third stage of creep.

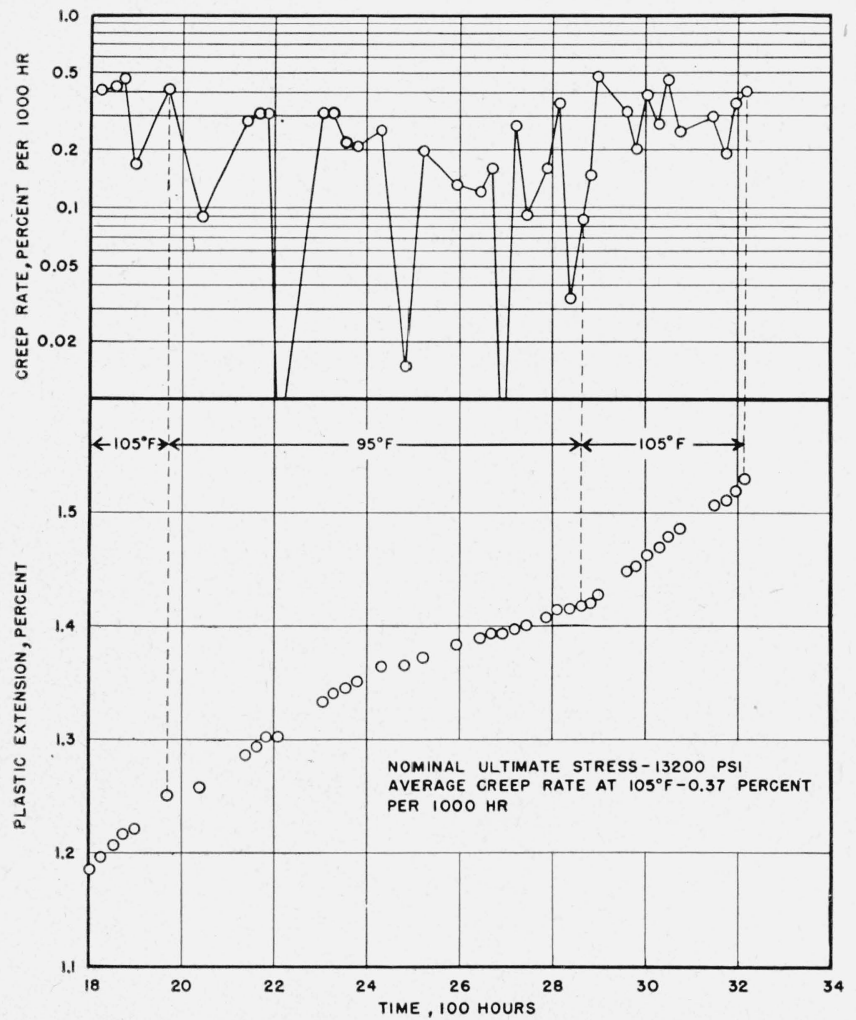

FIGURE 3. Extension-time and creep rate-time relations for a specimen tested with constant nominal stress of 13,200 psi, and temperature cycled between $105^{\circ}$ and $95^{\circ} \mathrm{F}$.

\section{Variation of Creep Rate With Plastic Extension}

The creep rate-plastic extension curves for two specimens tested with different initial stresses are illustrated in figure 4 . The values are plotted on a semilog basis. It is evident that the magnitude of the creep rate-strain cycles, when the data are plotted in this manner, is greater in the specimen strained at the lower stress (extension readings were made at equivalent time intervals). Furthermore, as is shown in the upper curve, after an initial adjustment period, the amplitude of the cycles becomes less until third stage conditions are approached. The strain-hardening process tends to

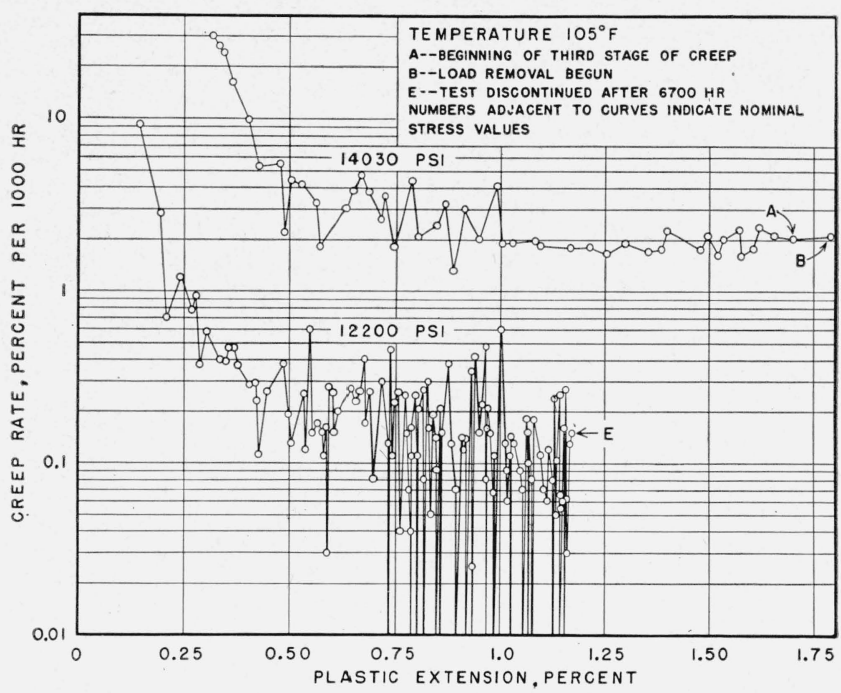

Figure 4. Variation in creep rate with plastic extension.

cause an increase and the recovery a decrease in the activation energy necessary for flow. Thus the time for attainment of each stage of creep is shorter as the applied stress is increased, and the deformation produced as a result of the metastable state adjusting itself toward a condition of lower free energy is greater. (For example, see fig. 2). In order for a decrease in free energy to occur, this system must undergo considerable atomic rearrangements. The mechanics of this process are illustrated by the serrations in these curves (fig. 4) and confirmed by subsequent metallographic examinations. The activation energy of the process is supplied in part by heat gain, the externally applied stress and localized internal thermal fluctuations. The cycling is also due in part to nucleation and growth of fracture sites.

Log-log creep rate-time curves for the intial stage of creep of two specimens tested with nominal stresses of 12,700 and $13,600 \mathrm{psi}$ are shown in figure 5. It is evident that both curves have approximately the same slope although at different levels. Such an equivalence tends to show that when the applied

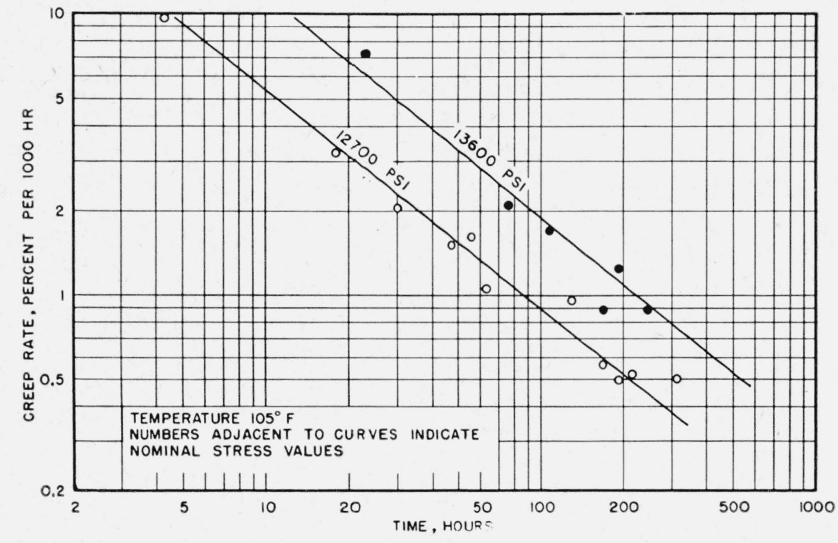

FIGURE 5. Variation in creep rate with time during first stage of creep. 
stresses are of the same order of magnitude, the mechanism of deformation is similar during the initial stage. Andrade [6], in his analysis of first stage conditions, concluded that with this type of plot, the curves should have a slope of minus $2 / 3$ when transient flow was the predominating characteristic. These two curves have a slope of about minus $2 / 3$, although such good agreement could not be obtained for the specimens at other stresses. Until the many types of flow have been clearly delineated, the application of these physical theories should be used with caution. Several competing and supporting mechanisms, dependent on the material, grain and crystallite size, total deformation and prior strain history, may be operating simultaneously.

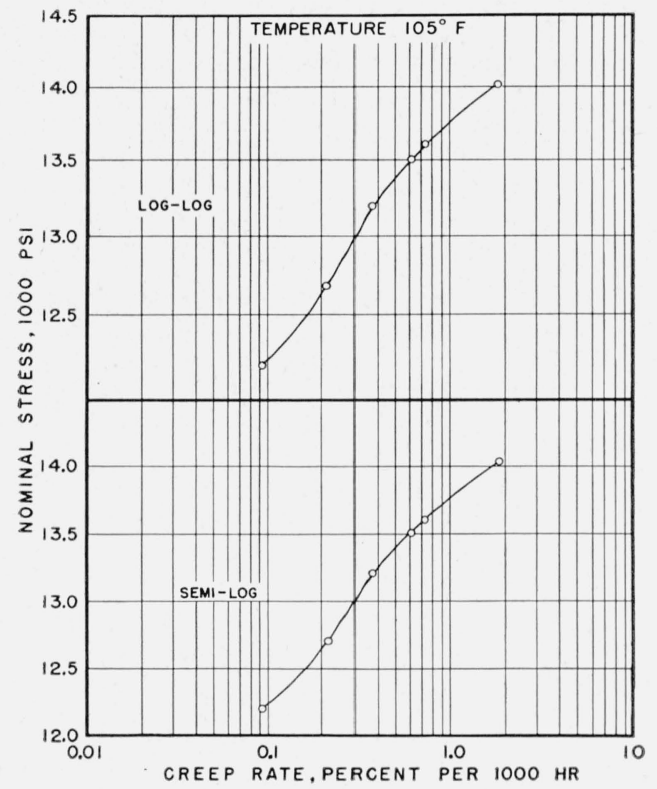

Figure_-6. Relationship between nominal stress and average creep rate during second stage of creep.

\section{Effect of Stress on Creep Rate in the Second Stage}

The relationship between the applied nominal stress and the average creep rate during the second stage is illustrated in figure 6 . Sigmoidal curves are produced when these values are plotted on either a log-log or semilog basis. It seems probable that either type of representation reflects the flow characteristics of the material. Only in those regions of stress in which the mechanism of deformation and the subsequent modes of fracture, transcrystalline or intercrystalline, are nearly equivalent, would linear relationships between the variables of stress and creep rate exist. Previously, it has been shown [3] that the size of the subcrystals produced as a result of plastic deformation vary inversely with the creep rate, and the tendency toward transcrystalline separation of the parent grains is greater the faster the speed of the process. Transcrystalline fracture predominates above the point of reversal in the stress-strain rate curve.

\section{Stress-Strain Relationships at Room Temperature}

McReynolds [7] in an analysis of stress-strain curves of aluminum tested in tension noted that macroscopic measurements almost invariably show a smooth curve of stress versus strain. Such homogeneity would indicate that discontinuities in strain on slip planes occur in increments too small to be recorded individually and in some manner independent of one another. However, as illustrated by a portion of the autographic stress-strain curve (fig. 7), inhomogeneity of deformation is reflected by the serrations (S) in this diagram for a tensile test conducted at $80^{\circ} \mathrm{F}$ with a rate of extension of 60,000 percent per $1,000 \mathrm{hr}$. This test was interrupted at various extensions and the load dropped to zero in order to evaluate the effects of the healing of the internal surfaces previously ruptured due to strain, on the subsequent work-hardening characteristics of the material. The test specimen was held at zero load during each interval for 10 mins before reloading at the same rate at which the specimen was originally loaded. The consequence of the ability of the atoms to rearrange themselves into a more stable system during the rest period was reflected after reapplication of load in the production of a "kink" (K, fig. 7) in the stress-strain curve. This phenomenon was observed and described previously by Farren and Taylor [8]. After the appearance of the kink, there appears to be a lag in stress before a continuous increase in rate of change of load with extension is noted (fig. 7). This lag extends over greater extension values the less the strain to which the specimen was subjected before the rest period. The rate of change of load with extension in the last part of the test appears to be independent of the load; however, multiaxial stresses due to the formation of a "neck" make further analysis difficult.

Whereas the above observations were based on nominal stress values, the true stress-strain curve reveals other interesting results, as is illustrated by figure 8 . The values are shown only to a true strain of about 0.9 due to the fact that beyond this strain, the specimen deformed with a quadrilateral contour at the base of the neck and microscopic cracks occurred at the axis of the specimen. These factors prevented quantitative determinations of the remaining area of the material. In figure $8, \mathrm{~A}$, the points at which the load was dropped to zero are indicated. The extension at maximum load was 1.4 percent - a value that was slightly less than the extensions obtained during the creep tests at the beginning of the third stage. It should be noted that the curve at $80^{\circ} \mathrm{F}$ becomes approximately horizontal for a limited range of true strain values immediately after maximum load. This indicates that the strain hardening in this strain range is zero. However, the contour of the curve between true strain values of 0.2 and 0.9 indicates that the strain-hardening increases slightly or becomes approximately constant. Some of these findings appear to confirm the conclusion of Farren and Taylor [8] that the ratio of the increase in internal energy to the work done is a 


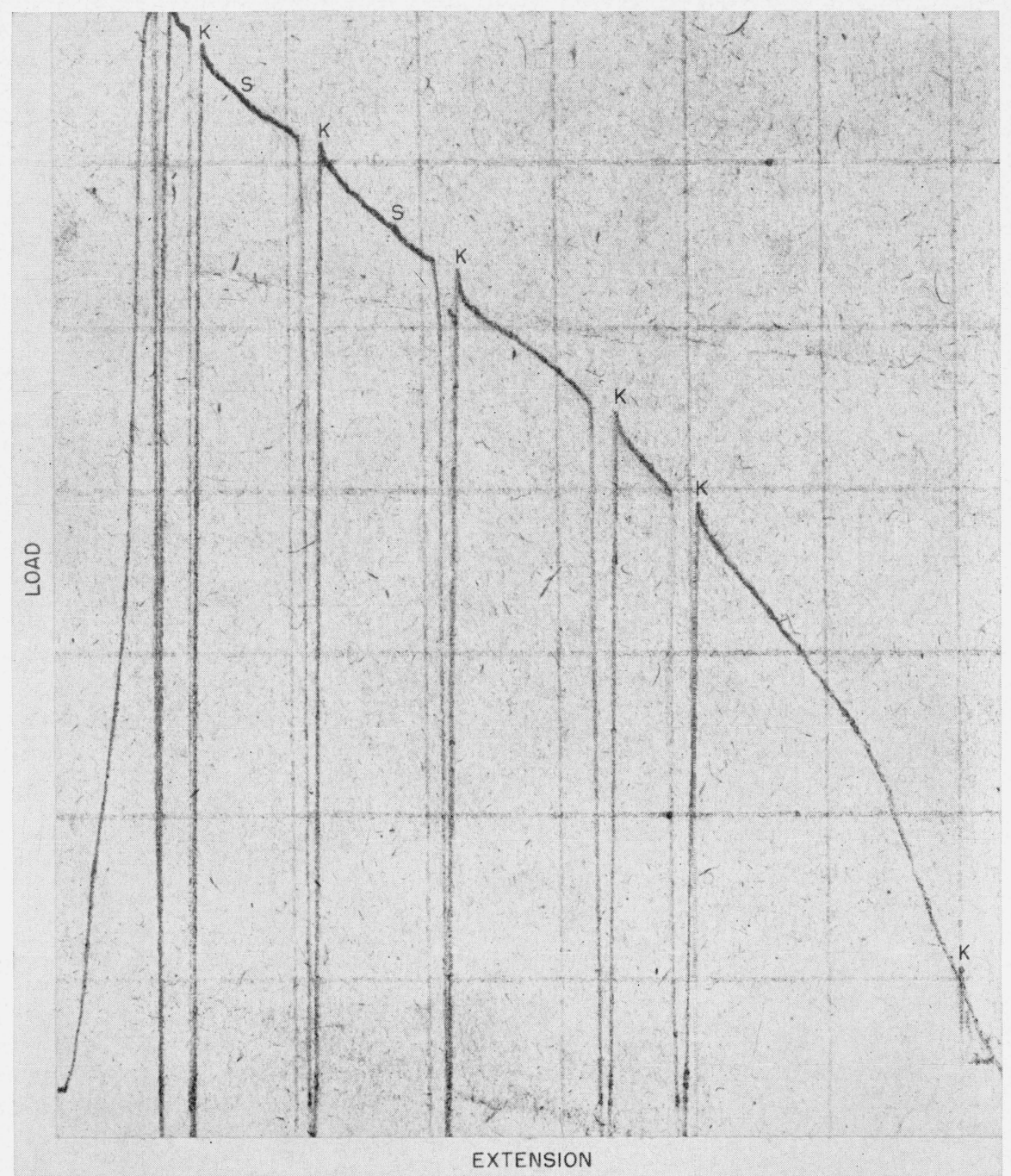

FIGURE 7. Autographic stress-strain diagram for interrupted tensile test at $80^{\circ} \mathrm{F}$.

constant. Enlarged scales were employed for plotting the data in the regions in which the specimen was unloaded and subsequently reloaded. These curves are reproduced in figure $8, \mathrm{~B}, \mathrm{C}, \mathrm{D}, \mathrm{E}$, and F. It is obvious that in spite of the occurrence of the kinks in the nominal stress-strain curve of figure 7 , the yield stress on reloading was lowered. In an analogous investigation, Cherian, Pietrokowsky, and Dorn [9] concluded that during the rest periods two types of recovery were evident. In one type, flow stress values on reloading are below those of the virgin material for all values of total strain. Fast reattainment of flow stress was evident in the test conducted with the creep specimen at two different temperatures (fig. 3). Slow reattainment of the original flow stress is apparent for the present tensile test (fig. 8). The change in extension at which the maximum flow stress is reattained after reloading is greater the higher the strain values at which the specimen was unloaded. Self recovery of the parent grains after deformation becomes more evident as the strain is increased.

\section{Microstructure and Fracture Characteristics}

The appearance of a fracture and some of the structural features accompanying deformation that led eventually to fracture of an aluminum specimen deformed at $80^{\circ} \mathrm{F}$ with a rate of extension of 60,000 percent per $1,000 \mathrm{hr}$ are shown in figures 9, 10, and 11. Necking of the specimen commenced immediately after maximum load was reached, and the cross-sectional area at the base of the neck continuously decreased to the end of the test. The appearance of the outer surfaces at fracture is shown in figure $9, \mathrm{~A}$. The general direction of granular elongation is outlined by the strain lines appearing at the surface. During the process of deformation the stress distribution was such that cracks (fig. 9, B) were nucleated at the axis of the specimen and propagated to the surface. As this process of deformation continued toward total fracture, the specimen finally exhibited a rim effect characterized by the extreme outer surface being the last portion to separate after considerable widening of the macro crack 

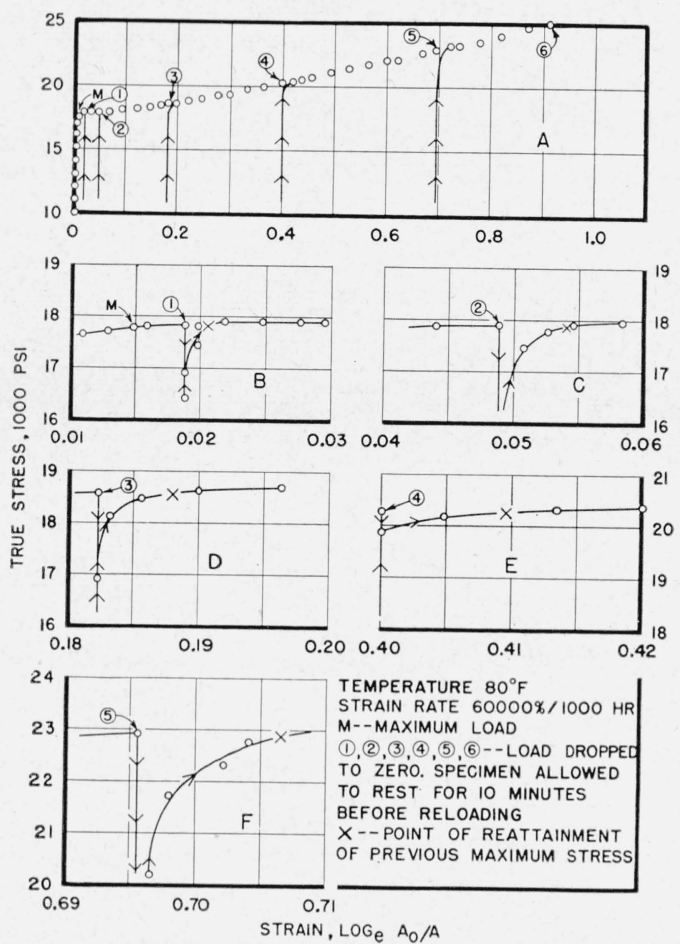

Figure 8. True stress-strain relationships for a specimen stressed interruptedly at $80^{\circ} \mathrm{F}$.

formed by the linking up of a number of microcracks in the interior. Figure 10, A, illustrates the structure representative of the original cold-drawn aluminum; the direction of the drawing is evident from the strain pattern. Some of the elongated grains appear to have broken up into small fragments due to the severity of the deformation, others are intact. As a result of testing in tension at a fast rate, the mode of fracture is essentially transcrystalline, as illustrated by figure 10, B. Transcrystalline cracks that did not link up to form the main fracture course are shown at various points in this region.

Figure 11 illustrates some of the etched patterns developed in areas near the axis of the specimen. The reduction of area in the region in which these photomicrographs were made was approximately 90 percent. Figure 11, A, shows some of the grains elongated in the direction of the applied stress and containing subcrystals. These substructures, according to Heidenreich [10], are fully developed reorientation domains corresponding to self-recovery after cold work. The absence of fracture through the grains in which these substructures were observed in the present study suggest that these grains are in a rather stable state; however, conditions in all grains were not favorable for the development of this substructure. Figure 11, B, illustrates the etch patterns developed in some of the grains that were not resolved into subcrystals. The strain markings, as shown, indicate that during the course of deformation a number of slip systems were active as would be predicted from the serrated stress-strain curves previously shown. The geometry and quantitative
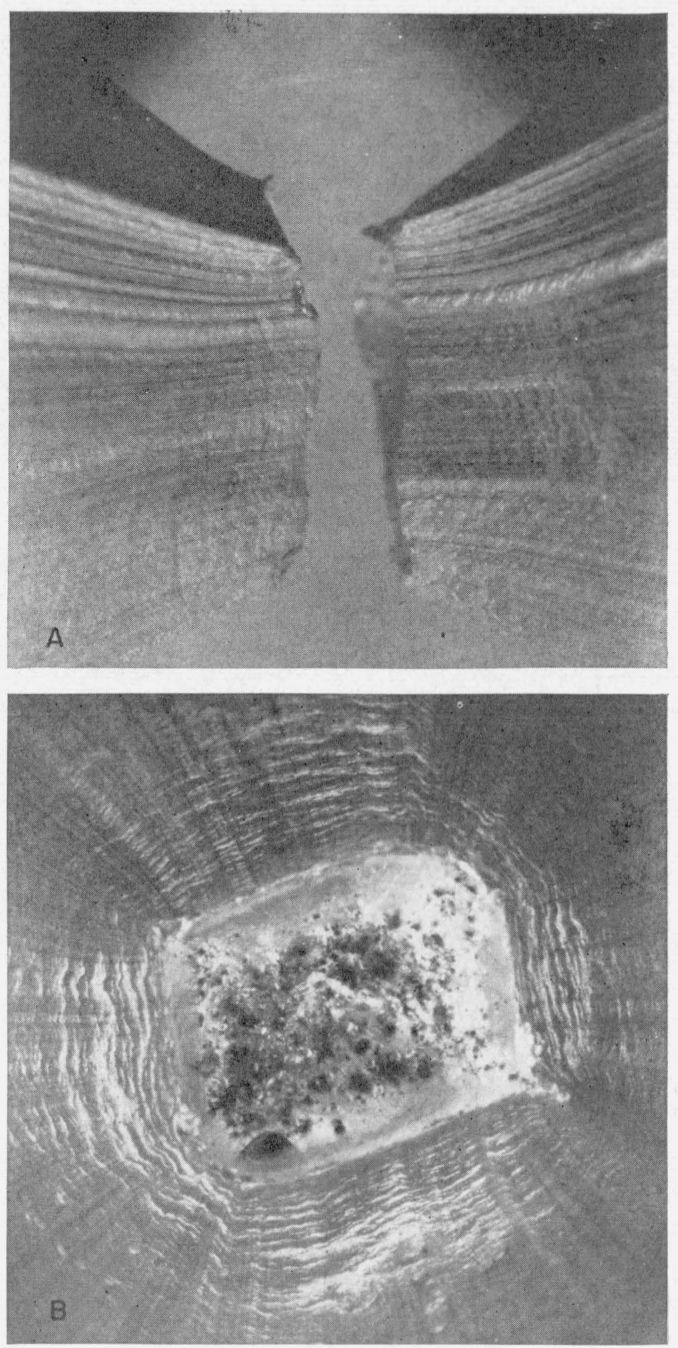

FiguRE 9. Photograph of the necked portion of a specimen after testing in tension at $80^{\circ} \mathrm{F}$.

A, $\times 10$ at fracture, longitudinal view; $B, \times 10$ at fracture, transverse view.

studies of the nucleation and growth of strain markings of this nature have been made by Barrett [11], Banerjee [12], Rosi and Mathewson [13] and Yen and Hibbard [14].

\section{Summary}

Tension tests were made on cold-drawn aluminum at $105^{\circ} \mathrm{F}$ at various creep rates.

Plastic extension at the beginning of the third stage was greater the higher the rate of extension in the second stage.

Cyclic temperature changes appeared to affect the mechanism of deformation and ductility at the beginning of the third stage to a greater degree than the second-stage creep rate.

Discontinuous flow was indicated by graphs obtained by plotting the logarithm of the creep rate against extension occurring during the course of each creep test. Discontinuous flow also was illustrated 

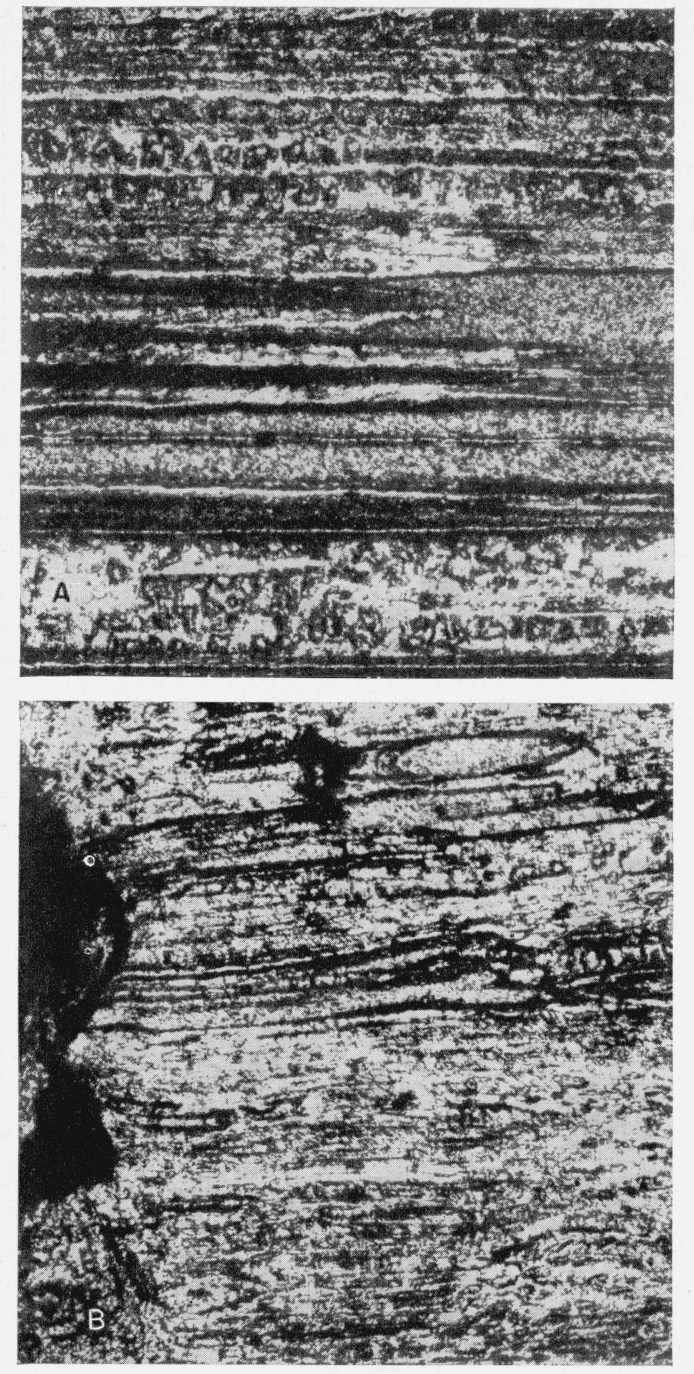

Figure 10. Structure before and after testing in tension at $80^{\circ} \mathrm{F}$.

A, Photomicrograph, $\times 100$, representative of structure before testing in tension longitudinal section, etched in 10 parts nitric acid (concentrated), 10 parts hydrochloric acid (concentrated), 3 parts hydrofluroic acid $(47 \%)$, and 77 parts water; tudinal section; same etchant as A.

by serrated stress-strain curves for a specimen tested at $80^{\circ} \mathrm{F}$.

Within a limited range of strain rates a slope of about minus $2 / 3$ was obtained in first-stage creep curves when transient flow was the predominant characteristic that is essentially in agreement with Andrade's conclusions.

Sigmoidal stress-creep rate curves were obtained when the data were plotted on either a log-log or semilog basis.

Yiẹld point lowering as evidence of recovery at room temperature in an interrupted tensile test served to confirm the results of previous investigations in this respect.

Self-recovery processes during deformation were illustrated by the breaking up of some of the parent grains into subcrystals of microscopic dimensions
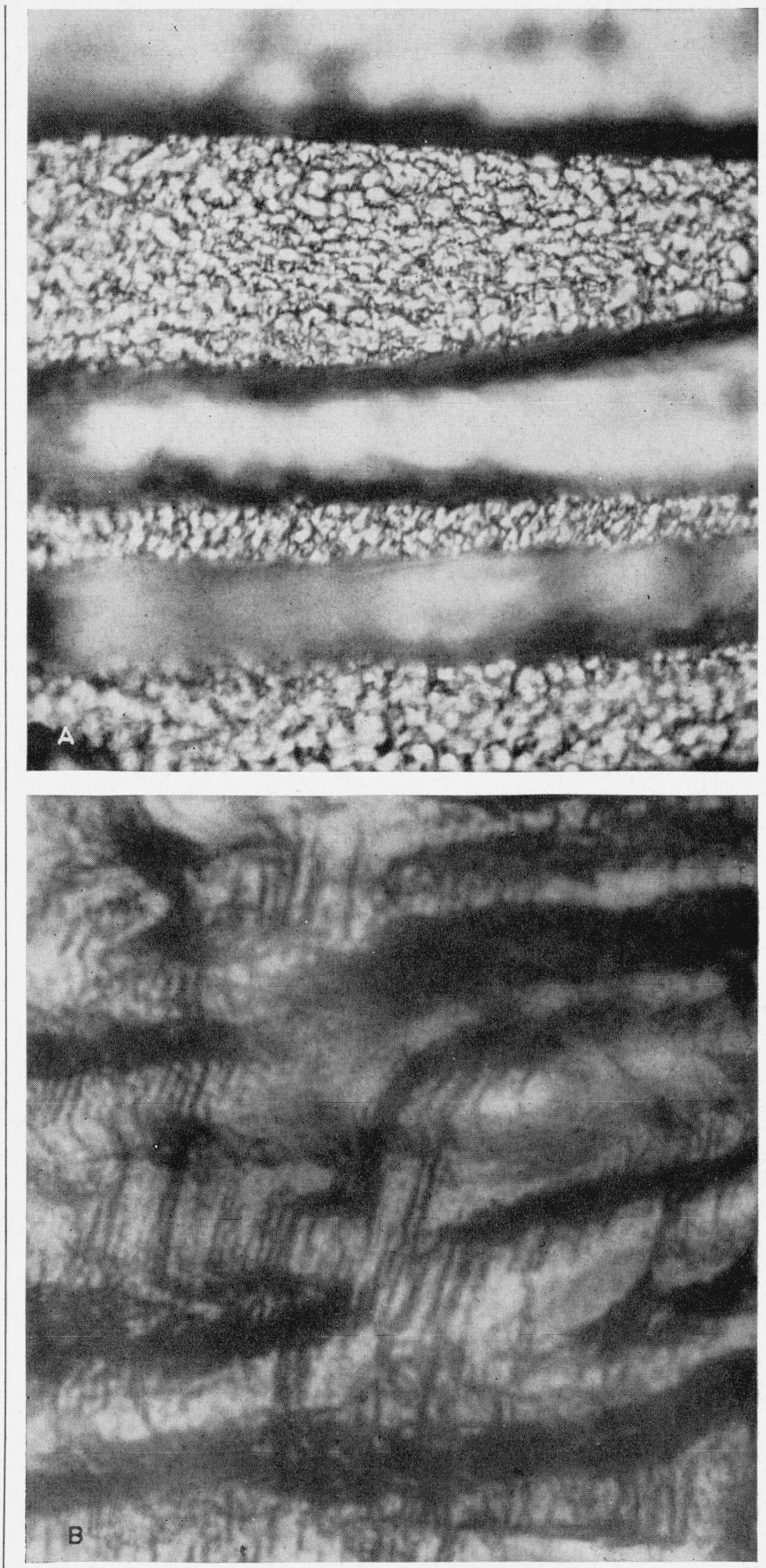

FiguRE 11. Intragranular structure of a specimen tested in tension at $80^{\circ} \mathrm{F}$ with a strain rate of 60,000 percent per 1,000 $\mathrm{hr}$; longitudinal sections, $0.1 \mathrm{in}$. from complete fracture, etched in 10 parts nitric acid (concentrated), 10 parts hydrochloric acid (concentrated), 3 parts hydrofluoric acid (47\%), and $7 \%$ parts water.

A, $\times 750$ showing subcrystallite structure; $B, \times 2,000$ showing slip bands and other strain markings.

and the occurrence of slip indicated by strain markings on other grains.

The author acknowledges the assistance of R. W. 
Mebs for his helpful discussion and of C. R. Johnson for making some of the measurements.

\section{References}

[1] P. Lacombe and L. Beaujard, The application of etch figures on pure aluminum to the study of some micrographic problems, J. Inst. Metals LXXIV, 1 (1948).

[2] G. R. Wilms and W. A. Wood, Mechanism of creep in metals, J. Inst. Metals, $\mathbf{7 5 ,} 693$ (1949).

[3] W. D. Jenkins and T. G. Digges, Creep of high-purity copper, J. Research NBS 45, 153 (1950) RP2121.

[4] W. D. Jenkins and T. G. Digges, Influence of strain rate and temperature on the creep of cold-drawn ingot iron, J. Research NBS 43, 117 (1949) RP2013.

[5] J. A. Bennett and D. J. McAdam, Jr., Creep rates of cold drawn nickel-copper alloy (Monel metal), J. Research NBS 28, 417 (1942) RP1462.

[6] E. N. da C. Andrade, The creep of metals, Report of a Conference on the Strength of Solids, Phys. Soc. 20 (1948).

[7] A. W. McReynolds, Plastic deformation waves in aluminum, J. Met. (Jan. 1949); Trans. AIME 185, 32 (1950).
[8] M. A. Farren and G. I. Taylor, The heat developed during plastic extension of metals, Proc. Roy. Soc. 107, 422 (1925).

[9] T. V. Cherian, P. Pietrokowsky, and J. E. Dorn, Some observations on the recovery of cold-worked aluminum, J. Met. (Dec. 1949); Metals Trans. 185, 948 (1950).

[10] R. D. Heidenreich, Structure of slip bands and coldworked metal, Seminar on the cold working of metals, Trans. Am. Soc. Metals 41-A, 57 (1949).

[11] C. S. Barrett, The crystallographic mechanisms of translation, twinning and banding, Seminar on the cold working of metals, Trans. Am. Soc. Metals 41-A, 65 (1949).

[12] B. R. Banerjee, A study of strain markings in aluminum, J. Met. (Sept. 1950); Trans. AIME 188, 1126 (1951).

[13] F. D. Rosi and C. H. Mathewson, A study of the plastic behavior of high-purity aluminum single crystals at various temperatures, J. Met. (Sept. 1950); Trans. AIME 188, 1159 (1951).

[14] M. K. Yen and W. R. Hibbard, Jr., The transverse bending of single crystals of aluminum, J. Met. Oct. (1949): Metals Trans. 185, 710 (1950).

Washington, November 1, 1950. 